\title{
Dynamics of Renal Histamine in Normal Rat Kidney and in Nephrosis Induced by Aminonucleoside of Puromycin
}

\author{
Hanna E. Abboud, S. L. Ou, J. A. Velosa, Sudhir V. Shah, and \\ Thomas P. Dousa, Nephrology Research Laboratories, Department of Physiology \\ and Biophysics, Division of Nephrology and Internal Medicine, Mayo Clinic \\ and Foundation, Rochester, Minnesota 55901
}

A B S T R A C T Histamine is known to have a profound effect on capillary permeability in nonrenal tissues and this effect is presumably mediated by cyclic (c)AMP. Because in our previous experiments we found that histamine stimulates cAMP accumulation in glomeruli (Torres, V. E., T. E. Northryn, R. M. Edwards, S. V. Shah, and T. P. Dousa. 1978. Modulation of cyclic nucleotides in isolated rat glomeruli. J. Clin. Invest. 62: 1334.), we now explored whether this amine is formed in renal tissue, namely in glomeruli, and whether its renal metabolism is altered in experimental nephrosis induced by puromycin aminonucleoside (PA) in rats. In normal rats, histamine content was higher $(\Delta+$ $240 \%)$ in cortex than in medulla. In glomeruli isolated from renal cortex, histamine content was significantly higher $(\Delta+260 \%)$ than in tubules. Incubation of isolated glomeruli with L-histidine resulted in a time-dependent increase of histamine content in glomeruli, but no change was found in tubules. The increase in glomerular histamine was blocked by the histidine decarboxylase inhibitor bromocresine. In rats with PA nephrosis induced by a single intraperitoneal injection of PA ( $15 \mathrm{mg} / 100 \mathrm{~g}$ body wt) urinary excretion of histamine was markedly increased $(>\Delta+200 \%)$, but control rats did not differ from rats with PA nephrosis in urinary excretions of $\mathrm{L}$-histidine and of creatinine. At the peak of proteinuria (day 9 after injection of PA) the plasma level of histamine was slightly elevated, and plasma histidine slightly decreased in animals that developed PA nephrosis. The content of histamine was markedly higher and the level of histidine was significantly lower in the renal cortex of PA-nephrotic rats as compared with controls; PA-nephrotic and control

Preliminary reports of this work were published as abstracts: 1979. Clin. Res. 27: 405A, and 1979. Kidney Int. 16: 781.

Received for publication 14 April 1980 and in revised form 8 October 1981.

Address reprint requests to Dr. Dousa. rats did not differ in the content of histidine and histamine in the liver. In addition, the content of histamine was higher in glomeruli isolated from PA-nephrotic rats; lesser difference was found in cortical tubules.

The results further indicate that PA-nephrotic rats have higher content of histamine in the renal cortex, predominently in glomeruli with increased urinary histamine excretion. The elevated renal cortical histamine is not due to higher availability of histamine precursor L-histidine. Results thus show that glomeruli are a major site of intrarenal histamine synthesis and accumulation, and also suggest that abnormal renal metabolism of this amine in PA nephrosis may be related, as a cause or as a consequence, to the pathogenesis of this disease.

\section{INTRODUCTION}

Nephrosis induced in rats by the administration of puromycin aminonucleoside (PA) ${ }^{1}$ closely resembles "nil lesion" or lipoid nephrosis in humans (1). Although the major ultrastructural and functional characteristics of both the human disease and its animal model were well described in recent studies (2-4), the pathogenetic mechanisms of the disease remain unknown (1).

Several features led us to consider that histamine may play an important role in the pathogenesis of PA nephrosis. In PA nephrosis, the major specific functional alteration is an increased permeability of glomerular capillary wall to negatively charged proteins (2-4). Observations in extrarenal tissues have shown that histamine increases the capillary permeability to macromolecules. For example, in rat mesentery, histamine increased both cyclic (c)AMP levels (5) and the

\footnotetext{
${ }^{1}$ Abbreviations used in this paper: $\mathrm{PA}$, puromycin aminonucleoside; cAMP, adenosine $3^{\prime}, 5^{\prime}$-cyclic monophosphate; KRB, Krebs-Ringer phosphate buffer.
} 
capillary permeability to albumin, with lesser changes in hydraulic permeability $(5,6)$; this effect of histamine has been duplicated by dibutyryl cAMP, suggesting that cAMP may mediate histamine action (5). A similar effect of histamine on permeability was observed in synovial membranes (7).

Studies that examined the renal effects of histamine administered into the systemic circulation or into the renal artery (8-12), although of value per se, provide little insight into the physiologic and pathogenic role of histamine at the level of the glomerulus. The effects of the infused amine on preglomerular and postglomerular vasculature precludes or complicates the interpretation of its local action on glomeruli. Moreover, and with few exceptions (13), the circulating levels of plasma histamine are very low (14). Hence, if histamine is formed within the kidney or released from infiltrating inflammatory cells or platelets, this locally formed or released histamine is more likely to modulate glomerular functions under physiological or even pathological conditions.

Whereas the kidney contains very few mast cells (15-17), some previous studies suggested that kidney tissue, mainly the renal cortex, contain an appreciable amount of histamine (18). In a general histochemical survey in tissues of the monkey (19), histamine was observed in glomerular capillaries. Histidine decarboxylase, the key enzyme in histamine biosynthesis, was found in glomeruli of rat kidney (20), suggesting that glomeruli may be a site of intrarenal histamine formation. Recently, we observed that histamine causes a striking dose-dependent increase of cAMP accumulation in isolated glomeruli (21-23), which is blocked by $\mathrm{H}_{2}$-receptor antagonists (21). These findings indicate the presence of $\mathbf{H}_{2}$-histamine receptors in glomeruli and are compatible with the possibility that histamine could be involved in the regulation of glomerular function an/or in the pathogenesis of glomerular disorders (24).

As an initial approach to define the potential role of histamine in glomerular pathophysiology, we investigated the content and/or accumulation of histamine in the renal cortex, glomeruli, and tubules; we also explored the dynamics of histamine in PA nephrosis-a disease with specific alterations of permselectivity of the glomerular capillary wall (1-4).

\section{METHODS}

Male Sprague-Dawley rats weighing $180-200 \mathrm{~g}$ had free access to food (Purina Laboratory Rat Chow, Ralston-Purina Co., St. Louis, Mo.) and tap water during the whole course of the experiment. For studies on histamine synthesis, glomeruli, tubules, and slices were prepared from kidneys of overnight-fasted rats.

Isolated glomeruli and cortical tubules. These tubules, as well as slices of renal cortex and medulla (outer and inner medulla taken together), were prepared in principle as described in our previous communication (21-23). Briefly, rats were anesthetized $(22,23)$, and the kidneys were perfused in situ with 60-80 ml of modified Krebs-Ringer Phosphate Buffer (KRB) of the following composition: $140 \mathrm{mM} \mathrm{NaCl}$, $5 \mathrm{mM} \mathrm{KCl}, 1.2 \mathrm{mM} \mathrm{MgSO}, 2.0 \mathrm{mM} \mathrm{CaCl}_{2}, 10 \mathrm{mM}$ glucose, $10 \mathrm{mM}$ sodium acetate, $2 \mathrm{mM}$ sodium phosphate, and 20 $\mathrm{mM}$ Tris ( $\mathrm{pH}$ 7.4) until surfaces were completely blanched, the kidneys were quickly excised, decapsulated, and placed in an ice-cold $\operatorname{KRB}(22,23)$. All subsequent preparative steps were performed at $4^{\circ} \mathrm{C}$.

In experiments where histamine content was measured in individed tissues, the cortex and medulla were immediately dissected by scissors and placed into 10 -ml glass homogenizer tubes (size A, Arthur H. Thomas Co., Philadelphia, Pa.) kept in crushed ice at $0^{\circ} \mathrm{C}$; tissues were then immediately homogenized (20 strokes) with a Teflon pestle in 9 vol of icecold $0.1 \mathrm{M}$ sodium phosphate buffer, $\mathrm{pH} 7.9$, referred to further as "phosphate buffer." A small aliquot of the homogenate was taken for protein determination; the rest was quickly frozen and stored overnight at $-20^{\circ} \mathrm{C}$; this freezing step ensures that histamine is released completely from homogenized tissue debris into the supernatant fluid (14).

Glomeruli and tubules. Glomeruli and tubules were prepared from renal cortical tissue by a combination of sieving and differential centrifugation as described in every detail in our previous reports $(22,23)$. The purity of each glomerular suspension was evaluated by light microscopic examination and by counting of glomeruli as described (2123). Criteria for purity of glomeruli were the same as in our previous studies (21-23). Glomerular and tubular preparations were then pelleted by centrifugation at $1,500 \mathrm{~g}$ for 5 min, gently resuspended in phosphate buffer, and transferred to preweighted polyallomer tubes to determine the approximate wet weight of the preparations. To determine histamine content in glomeruli and tubules, freshly prepared glomeruli and tubules (wet wt of each, $\sim 25-30 \mathrm{mg}$ ) were then immediately homogenized with a Teflon pestle in $1-\mathrm{ml}$ glass homogenizer tubes (size $\mathbf{0}$, Arthur $\mathbf{H}$. Thomas Co.) in phosphate buffer in a similar way as for tissue slices; an aliquot was taken for protein determination, and the rest was frozen overnight at $-20^{\circ} \mathrm{C}$ for histamine analysis, as for tissue slices.

Accumulation of histamine in isolated glomeruli and tubules. Incubations of freshly prepared glomeruli and tubules, from either control or PA-nephrotic rats, (wet wt, 12-15 mg) were carried out using a method analogous in principle to that of Slovach and Uvnas (25).

Incubations were carried out in polypropylene tubes (17 $\times 100 \mathrm{~mm}$, Falcon Labware, Div. Becton, Dickinson \& Co., Oxnard, Calif.). The incubation medium consisted of a buffered medium, total volume, $1 \mathrm{ml}$, containing the following components: $154 \mathrm{mM} \mathrm{NaCl}, 2.7 \mathrm{mM} \mathrm{KCl}, 0.8 \mathrm{mM} \mathrm{CaCl}_{2}$, $0.1 \%$ glucose, $67 \mathrm{mM} \mathrm{Na} 2 \mathrm{HPO}_{4}$, and $\mathrm{KH}_{2} \mathrm{PO}_{4}$ adjusted to pH 7.2. The incubation mixture also contained $1 \mathrm{mM} \mathrm{L}$ histidine as histamine substrate, $0.1 \mathrm{mM}$ pyridoxal phosphate coenzyme of histidine decarboxylase (26), $0.1 \mathrm{mM}$ aminoguanidine (histaminase inhibitor) (26). This concentration of $L$-histidine $(1 \mathrm{mM})$ was chosen in order to insure saturation of histidine decarboxylase, based on a previous report (20). Incubations were carried out under nitrogen atmosphere in the presence or absence of $0.1 \mathrm{mM}$ bromocresine (a specific histidine decarboxylase inhibitor) $(26)$ at $37^{\circ} \mathrm{C}$ for 0,90 , and $180 \mathrm{~min}$ in a Dubnoff shaking water bath $(60 \mathrm{cycles} / \mathrm{min})$. In addition, the tubes were also shaken manually every 30 $\min (25)$ during the incubation. The substrate $(1 \mathrm{mM}$ L-his- 
tidine) was always added last to the incubation mixture immediately before commencing the incubation. In each experiment, blank incubations were run using glomerular and tubular suspensions, which were heated in boiling water bath for $10 \mathrm{~min}$ before the addition of the substrate in order to inactivate the enzymes $(27,28)$. At the end of incubation, the reaction was stopped by heating the tubes in a boiling water bath for $10 \mathrm{~min}$ to inactivate the enzymes $(27,28)$. In preliminary experiments, we found that boiling does not alter histamine levels in renal tissue, as reported for most other tissues $(14,29)$. The content of the tubes was then homogenized wih Teflon pestle and a small aliquot of the whole homogenate was also taken for the determination of protein; the samples were then frozen and stored overnight at $-20^{\circ} \mathrm{C}$, before histamine determination by double isotope assay (see below) (14).

In studies on PA nephrosis, rats had ad lib. access to drinking tap water and regular rat diet (Purina Laboratory Rat Chow, Ralston-Purina Co.). They were housed in individual metabolic cages, and weight and urine flow rates were measured daily. After a 3-d equilibration period, 24-h base-line (day 0) urinary histamine and urinary protein was measured. PA nephrosis was then induced by a single intraperitoneal injection of $15 \mathrm{mg} / 100 \mathrm{~g}$ body wt (30), PA was dissolved in isotonic $\mathrm{NaCl}$. Control rats were injected with an equivalent volume of isotonic $\mathrm{NaCl}$. Development and progression of the disease was monitored by daily urine collection (in 100 $\mu \mathrm{l}$ of $6 \mathrm{~N} \mathrm{HCl}$ to prevent bacterial growth) and measurements of urinary protein. In addition to urinary content of histamine, 24-h urine content of histidine, protein, and creatinine were measured on day 9 after PA injection (around the peak of proteinuria). Urine samples were frozen at $-20^{\circ} \mathrm{C}$ until assayed (14).

To examine the time-course of urinary histamine excretion and to determine tissue levels of histidine and histamine, another group of rats was studied. Both the control and experimental rats in this study were treated in an identical manner to the first group. A 24-h urinary histamine excretion was measured on day 0 , day 3 , day 5 , and day 9 after PA injection (around the peak of proteinuria). At the end of the experiment, rats were anesthetized by pentobarbital $50 \mathrm{mg} /$ kg i.p. The abdomen was opened through a midline incision and a cortical slice was obtained from the right kidney. Simultaneously a piece of liver tissue was obtained; a small portion of the renal tissue was frozen and fixed for morphological studies. The rest of the renal cortical tissue was placed into separate $10-\mathrm{ml}$ glass homogenizer tubes and immediately homogenized in ice-cold sodium phosphate buffer (as described above), an aliquot was taken for protein measurement, and the homogenate was then divided into two aliquots: one for measurement of histidine and the other one for histamine; homogenate was then frozen and stored at $-20^{\circ} \mathrm{C}$. Liver tissue was processed in the same way. Immediately after the excision of renal cortical and liver tissue, blood was drawn from the aorta through a flexible plastic cannula. The first five drops were discarded and blood was then collected in a heparinized plastic syringe. Blood samples were distributed into polypropylene tubes. These were centrifuged immediately at $900 \mathrm{~g}$ for $20 \mathrm{~min}$ in a refrigerated centrifuge to separate plasma (31). Although this speed centrifugation does not pellet platelets completely, this was not necessary in the present study because rat platelets (similar to human and unlike rabbit platelets) do not contain histamine (32). Histamine content in plasma, urine, and tissues (including glomeruli and tubules) was determined by the double-isotope radioenzyme assay as described in detail by Beaven et al.(14).
Assays. The histamine double-isotope radioenzyme assay was carried out as described by Beaven and Horakova (14). Fig. 1 shows a calibration curve of histamine standards for a typical experiment. The assay used was linear between 0.275 and $11.0 \mathrm{ng}$ histamine per sample or standard. Bromocresine, aminoguanidine, and L-histidine were tested and did not interfere with the assay. Pipetting and dilutions of histamine were performed with plastic Eppendorf pipettes (Brinkmann Instruments, Inc., Westbury, N. Y.) in polypropylene containers to avoid loss of histamine by adsorption to glass (33).

For determination of tissue histamine, the frozen homogenates of tissue in phosphate buffer were thawed and centrifuged at $2,000 \mathrm{~g}$ for $20 \mathrm{~min}$ and supernatant fluid was used for assay (14). For histamine content in liver tissue, renal cortical tissue slices, glomeruli, and tubules, $50 \mu$ l of supernatant of homogenate was used for assay. For histamine accumulation experiments in glomeruli or tubules, $300 \mu \mathrm{l}$ of supernatant (from both control and experimental tubes) was brought up to $\mathrm{pH} 7.9$ by $0.1 \mathrm{~N} \mathrm{NaOH}$ and used for the assay.

For plasma histamine determination $50 \mu$ l of undiluted sample was used for the assay. Because rats with fully developed PA nephrosis have hyperlipidemia (34), the possibility that the elevated plasma lipids might interfere with the assay was tested. Histamine in plasma samples of nephrotic rats from which lipids were removed by ultracentrifugation $(100,000 \mathrm{~g}$ for $\mathrm{l} \mathrm{h})$ and clear infranatants did not differ from nontreated samples in histamine content or in percent recovery of histamine. For urine histamine, $20 \mu \mathrm{l}$ of undiluted sample was used. To exclude the interference of proteinuria with histamine determination, the assay was carried out in samples before and after deproteinization by the addition of $0.5 \mathrm{M}$ perchloric acid, which was later precipitated by $\mathrm{KOH}$ and precipitate separated (35). Presence of protein did not influence content or percent recovery of histamine. To validate specificity of the histamine determinations, some tissue samples and standards were incubated with hog kidney histaminase (33) and subsequently assayed for histamine as follows: unlabeled histamine (final concen-

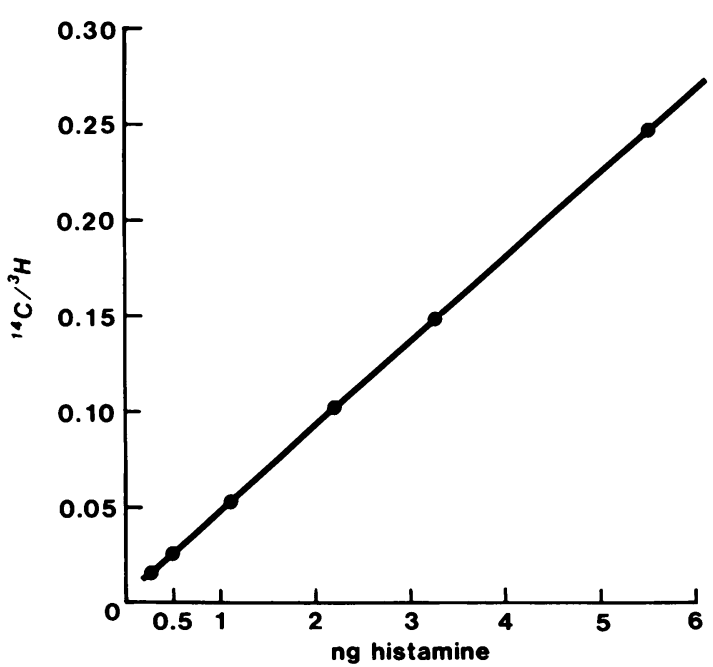

Figure 1 Relationship between histamine concentration and ${ }^{14} \mathrm{C} /{ }^{3} \mathrm{H}$-methyl-histamine radioactivity (dpm) in the double-isotope radioenzyme assay for hisamine. Abscissa: nanograms of histamine standards; ordinate: ${ }^{14} \mathrm{C} /{ }^{3} \mathrm{H}$ ratio of methyl-histamine. 
tration $1 \mu \mathrm{M})$ and sample from urine $(20 \mu \mathrm{l})$, tissue, and plasma $(50 \mu \mathrm{l})$ were incubated with $100 \mu \mathrm{l}$ of hog kidney histaminase (enzyme preparation reconstituted with $0.1 \mathrm{M}$ $\mathrm{Na}$ phosphate buffer $\mathrm{pH} 7.2$ to give a concentration of 6 $\mu \mathrm{g} / 100 \mu \mathrm{l})$. The incubations were carried out in $0.1 \mathrm{M} \mathrm{Na}$ phosphate buffer, $\mathrm{pH} 7.2$, in a total volume of $1 \mathrm{ml}$ at $37^{\circ} \mathrm{C}$ in shaking water bath for $5 \mathrm{~h}$. Aminoguanidine $0.1 \mathrm{mM}$ was added to the incubation to stop the reactions. Control tubes were incubated with boiled preparation of histaminase to inactivate the enzyme (33). At the end of the incubation the mixture was centrifuged and a $50-\mu \mathrm{l}$ aliquot of supernatant was assayed for histamine as per above. Counts of radioactivity representing histamine in samples or standards incubated with histaminase were reduced to blank levels. Average percent recovery for urine and renal tissue histamine (including the accumulation experiments in glomeruli and tubules) was $45-50 \%$; that for liver ranged from 35 to $40 \%$, similar to the experience of Beaven et al. (36).

A soluble preparation of bacterial histidine decarboxylase was prepared as described in detail by Beaven and Jacobsen (33) fromı acetone-dried powder of clostridium welchii. The $\beta-{ }^{3} \mathrm{H}$-labeled histamine was extracted according to the procedure of Shore et al. (37) and adjusted in $0.1 \mathrm{~N} \mathrm{HCl}$ to give a concentration of $1 \mathrm{mCi} / \mathrm{ml}$. This solution was then stored in $100-\mu \mathrm{l}$ aliquots in conical centrifuge polypropylene tubes at $-20^{\circ} \mathrm{C}$. Histamine methyl transferase (HMT) was prepared from freshly frozen adult male guinea pig brains (purchased from Pel-Freeze Biologicals, Rogers, Ark.) according to the ammonium sulphate purification method of Brown et al. (38). The final preparation $(10 \mathrm{mg}$ protein $/ \mathrm{ml}$ ) was divided into aliquots and stored in polypropylene vials at $-20^{\circ} \mathrm{C}$. Hog kidney histaminase $(0.12 \mathrm{U} / \mathrm{mg})$ was purchased from Sigma Chemical Co., St. Louis, Mo.

Histidine content in plasma, urine, and tissues was measured by fluorometric assay, which involves condensation of histidine with ophthaldehyde (39). Briefly a 250-300- $\mu$ l aliquot of tissue homogenate was deproteinized by adding an equal volume of $0.6 \mathrm{~N}$ TCA, then centrifuging the mixture for $15-20 \mathrm{~min}$ at $900 \mathrm{~g}$; an aliquot of the supernatant was further diluted $\times 5$ with distilled water (final TCA concentration, $0.06 \mathrm{~N}$ ). $500 \mu \mathrm{l}$ of the diluted sample was added to the incubation tubes. Standards were prepared in $0.06 \mathrm{~N}$ TCA. Standards and samples were read at $360-\mathrm{nm}$ activation and 436-nm emission wavelength (Aminco-Bowman spectrophotofluorometer, American Instrument Co., Silver Spring Md.) (39). Tissue protein was determined by Lowry's method (40) as in our previous studies (211-33). Urinary and plasma protein content was determined by biuret method (41). Plasma and urinary creatinine was measured by standard colorimetric method using picric acid (42) as in our previous studies (43).

Renal tissue samples were fixed in formol and sections stained by hematoxylin-eosin method. Aliquots of the tissue were frozen, sections cut in cryostat, and then stained with coloidal iron (44).

Results were statistically evaluated by $t$ test for group or paired comparisons as appropriate. Values of $P>0.05$ were considered nonsignificant.

Materials. Puromycin aminonucleoside, 6-dimethylamino-9-[amino-3'-deoxyribosyl] purine (PA) was purchased from ICN Nutritional Biochemicals, Cleveland, Ohio. $[(\beta-$ side-chain label) $\left.{ }^{3} \mathrm{H}\right]$ histamine was prepared by the decarboxylation of ( $\beta$-side chain label) $\mathrm{L}-\left[{ }^{3} \mathrm{H}\right]$ histidine $(10 \mathrm{Ci} /$ mmol) (New England Nuclear Corp. Boston, Mass.) as in Methods. $S$-adenosyl-L $\left[\right.$ methyl $\left.-{ }^{14} \mathrm{C}\right] \mathrm{methionine} 62 \mathrm{mCi} / \mathrm{mmol}$ was obtained from Amersham Corp., Arlington Heights, Ill. Nonlabeled histamine dihydrochloride, pyridoxal phosphate, and L-histidine were purchased from Sigma Chemical
Co. Aminoguanidine sulphate was purchased from Eastman organic chemicals, Eastman Laboratory and Specialty Chemicals, Eastman Kodak Co., Rochester, N. Y.). Nonradioactive 1-methyl-4-(2-aminoethyl)-imidazole hydrochloride (methylhistamine) from Calbiochem-Behring Corp., San Diego, Calif. Bromocresine (4-bromo-3-hydroxybenzylozy-amine dihydrogen phosphate) was kindly supplied by Lederle Laboratories, Div. American Cyanamid Co., Pearl River, N. Y.

\section{RESULTS}

Histamine was measured in the renal cortex and medulla dissected from the same kidney; tissues were dissected, processed, and assayed for histamine at the same time. The cortical content of histamine was significantly higher compared with the medulla (Fig. 2). To learn whether histamine is predominently localized in the cortex, glomeruli and tubules were prepared using the procedure described in Methods and histamine content was determined. Compared with tubules, histamine content was significantly higher in glomeruli (Fig. 2, Table II)

To determine whether the higher content of histamine in glomeruli was due to endogenous formation, glomeruli (and for comparison tubules) isolated from the same kidneys were incubated with the histamineprecursor, L-histidine, the substrate of histidine decarboxylase (45), and with appropriate cofactors. Incubations with L-histidine for 1.5 and $3 \mathrm{~h}$ caused a significant increase in histamine content in the glomerular suspension, which was proportional to the time of incubation (Fig. 3). When glomeruli were inactivated by heating for $10 \mathrm{~min}$ in a boiling water bath before incubation with L-histidine, no increase in histamine was detected. Similarly, there was no accumulation of histamine in incubations of glomeruli or tubules $(3 \mathrm{~h})$ carried out in the absence of L-histidine; the level of histamine was actually decreased (data not shown). In contrast to glomeruli, suspension of cortical tubules prepared from the same kidney, and incubated with L-histidine under identical conditions as glomeruli showed no change in histamine content (Fig. 3).

We then tested whether the differences between glomeruli and tubules in the capacity to accumulate histamine was due to different rate of de novo histamine synthesis from L-histidine, rather than due to other factors. The effect of bromocresine, an inhibitor of histidine decarboxylase $(26,45)$, on histamine accumulation was examined. Addition of bromocresine blocked the accumulation of histamine in glomeruli incubated with L-histidine (Fig. 3), but had no effect on histamine content in tubules incubated with $\mathrm{L}$-histidine.

The metabolism of histamine was then examined in rats with PA nephrosis induced by a single i.p. injection of PA; histamine and histidine levels in plasma and urine were determined around the peak of proteinuria. 

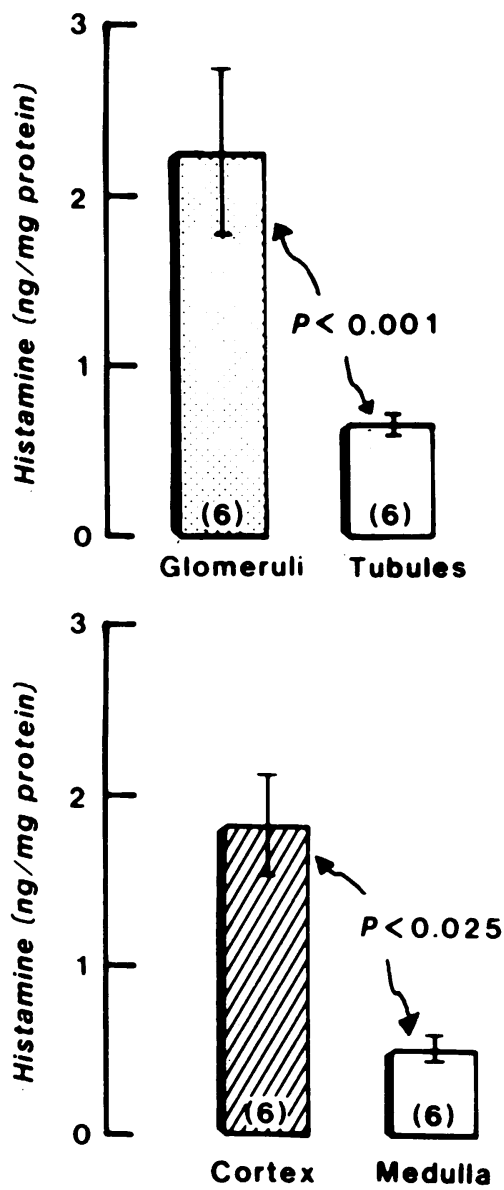

Figure 2 Upper panel: Content of histamine in glomeruli and cortical tubules. Dotted bar, glomeruli; open bar, tubules. Each value is based on mean \pm SEM of six experiments. Glomeruli and tubules were prepared simultaneously as described in Methods. Values are mean \pm SEM of six experiments; each histamine determination was done in two aliquots of homogenate each analyzed in duplicate. Lower panel: Histamine content in renal cortex (shaded bar) and medulla (open bar). $P$ value denotes significance of difference between cortex and medulla or between glomeruli and tubules, $t$ test.

Animals were sacrified after the development of proteinuria (Fig. 4), on day 9 after PA injection, and plasma and urine were analyzed for their content of histamine and histidine. Rats with fully developed proteinuria had ascites, hypoproteinemia, and slightly elevated plasma creatinine levels but did not differ in urinary excretion of creatinine (Table I) or in estimated creatinine clearance. ${ }^{2}$ Histological examination (by hematoxylin-eosin stain) showed no apparent

${ }^{2}$ Plasma creatinines were obtained at the end of the urine collection period at time of sacrifice. Estimated creatinine clearances milliliter per minute (mean $\pm \mathrm{SE}$ ) were in controls: $0.886 \pm 0.0062(n=19)$ and in PA nephrosis $0.769 \pm 0.008$ ( $n$ $=20$ ). pathologic changes, but rats with PA nephrons had a marked decrease in intensity of glomerular staining with colloidal iron (44).

On day 9 after PA injection there was a marked increase in urinary histamine excretion in PA rats as compared with controls (Table I) at a time when plasma levels of histamine were only slightly higher in the nephrotic rats than in controls (Table I). The filtered load of histamine was assessed from creatinine clearance and plasma histamine levels in individual rats. The amount of filtered histamine in control rats $(16.9 \pm 2.2 \mu \mathrm{g} / 24$ per $\mathrm{h}$ g body $\mathrm{wt}$; mean $\pm \mathrm{SE})$ was not significantly different from PA rats $(15.6 \pm 1.0 \mu \mathrm{g} / 24$ $\mathrm{h}$ per $100 \mathrm{~g}$ body $\mathrm{wt}$; mean $\pm \mathrm{SE}$ ). The urinary excretion of the histamine substrate L-histidine was not different between the two groups, whereas plasma levels of histidine were even slightly lower in the PA-nephrotic rats (Table I). Likewise, the filtered load of L-histidine ( $\mathrm{mg} / 24 \mathrm{~h}$ per $100 \mathrm{~g}$ body wt) was slightly lower in PA rats $(2.30 \pm 0.21$; mean $\pm S E)$ than in control rats (3.04 \pm 0.25 ; mean $\pm \mathrm{SE})$. These comparisons suggest that the substrate (L-histidine) availability is not the cause of the elevated histamine levels.

The urinary excretion of histamine during the progression of the disease, and tissue levels of histamine and histidine, were studied in another group of rats with PA nephrosis induced exactly as in the first group.

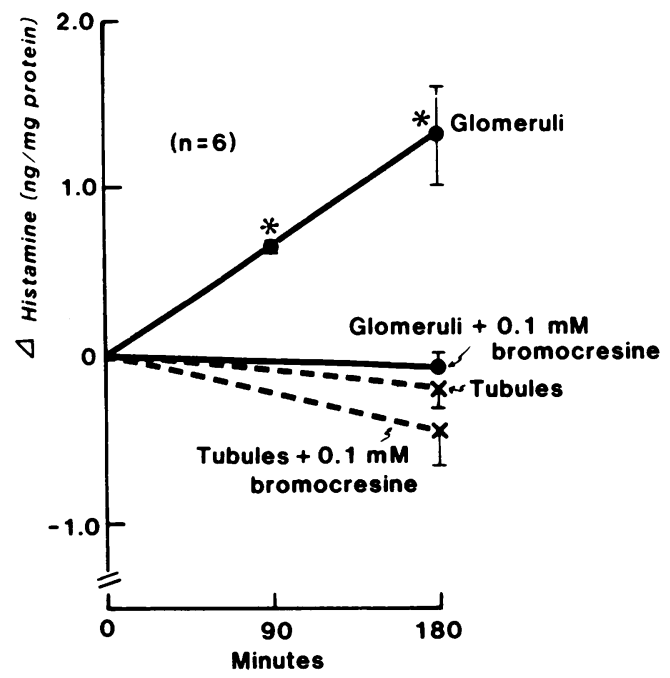

Figure 3 Changes in histamine content in glomeruli (solid lines) and in tubules (broken lines) after incubation wtih $1 \mathrm{mM}$ L-histidine. Abscissa: incubation time; ordinate: difference $(\Delta)$ in histamine content (nanograms histamine/ per milligram protein) compared with value at 0 incubation time (for details see Methods). Each point denotes mean \pm SEM of six experiments. Asterisk denotes values (increase in histamine) significantly different $(P<0.02$ or higher level of significance; paired $t$ test) compared with corresponding value at 0 time of the same preparation. Histamine content in glomeruli at 0 time was $1.99 \pm 0.26 \mathrm{ng} / \mathrm{mg}$ protein, that in tubules $1.36 \pm 0.19 \mathrm{ng} / \mathrm{mg}$ protein. 


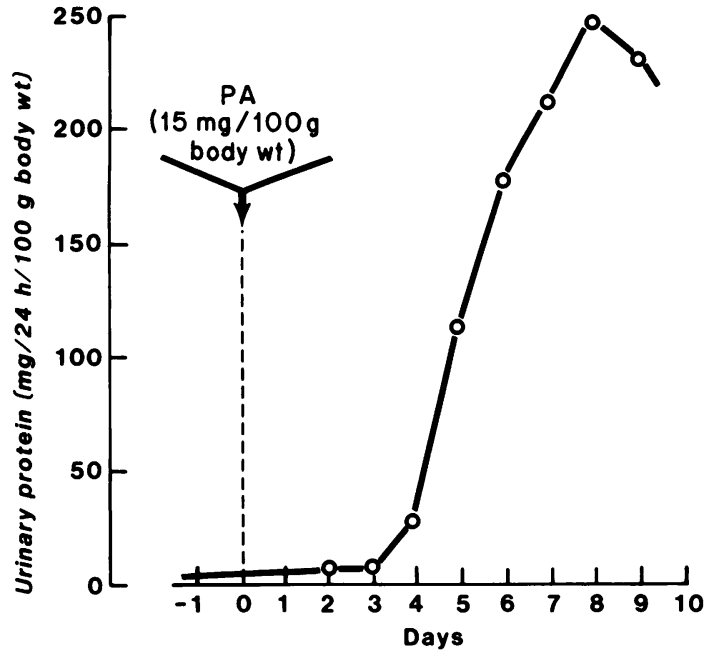

Figure 4 Development of proteinuria in rats injected with puromycin animonucleoside (PA) on day 0 . Each point represents mean of 22 animals.

The time-course and extent of proteinuria (Table I) in this group was virtually identical to the first experiment; at day 9 protein excretion in PA nephrotic animals was $232.1 \pm 19.9 \mathrm{mg} / 24 \mathrm{~h}$ per $100 \mathrm{~g}$ body wt, mean \pm SEM; $n=17$. Urinary excretion of histamine progressively increased in PA-nephrotic rats compared wtih basal value at day 0 , starting on day 5 after PA injection ( $2 \mathrm{~d}$ after the onset of poteinuria), reaching its highest levels on day 9 (around the peak of proteinuria) (Fig. 5). The urinary excretion of histamine in the control rats did not differ from control period (day 0) throughout the experiment (Fig. 5). Urinary histamine excretion were also significantly higher in PA-nephrotic rats compared with controls on both days 7 and 9 after PA injection (Fig. 5). The magnitude of difference in urinary histamine excretion between PAnephrotic and control rats (controls: $2806 \pm 725$ vs. PA nephrosis: $6336 \pm 946 \mathrm{ng}$ histamine $/ 24 \mathrm{~h}$ per $100 \mathrm{~g}$ body wt; mean \pm SEM; $P<0.005, t$ test) on day 9 (Fig. 5) were very similar to that observed in the first experiment (see Table I).

On day 9, the animals were killed and histidine and histamine levels were determined in kidney cortex and liver. Rats with PA nephrosis did not differ from controls in histidine or histamine content of liver tissue (Fig. 6). On the other hand, histamine content in the renal cortical tissue of PA-nephrotic rats was markedly higher (Fig. 6) and the histidine content was lower than in kidney cortex of controls (Fig. 6).

Finally, histamine content was measured in glomeruli and tubules isolated from control and PA-nephrotic rats. The disease was induced as in previous

TABLE I

Urinary Excretion and Plasma Levels of Histamine, Histidine, and Other Parameters of Renal Function in 18 Control Rats and in 22 Rats with PA Nephrosis at Day 9 after Injection of PA. For Details See Methods.

\begin{tabular}{|c|c|c|c|}
\hline & \multicolumn{3}{|c|}{ Plasma values } \\
\hline & Controls & PA nephrosis & $P$ value ${ }^{\circ}$ \\
\hline Plasma protein, $m g / d l$ & $6.17 \pm 0.28 \ddagger$ & $4.76 \pm 0.09$ & $<0.005$ \\
\hline Plasma creatinine, $m g / d l$ & $0.86 \pm 0.07$ & $1.08 \pm 0.05$ & $<0.01$ \\
\hline Plasma histamine, $n g / m l$ & $28.97 \pm 2.33$ & $32.93 \pm 2.28$ & NS \\
\hline \multirow[t]{3}{*}{ Plasma histidine, $\mu g / m l$} & $5.26 \pm 0.12$ & $4.72 \pm 0.12$ & $<0.05$ \\
\hline & \multicolumn{3}{|c|}{ Urinary values } \\
\hline & Controls & PA nephrosis & $P$ value ${ }^{\bullet}$ \\
\hline Urine protein, $m g / 24 \mathrm{~h} / 100 \mathrm{~g}$ body $w t$ & $2.3 \pm 0.4$ & $229.0 \pm 17.5$ & $<0.001$ \\
\hline Urine creatinine, $m g / 24 \mathrm{~h} / 100 \mathrm{~g}$ body $w t$ & $4.63 \pm 0.29$ & $5.2 \pm 0.32$ & NS \\
\hline Urine histamine, $n g / 24 \mathrm{~h} / 100 \mathrm{~g}$ body $w t$ & $2344 \pm 482$ & $6430 \pm 860$ & $<0.001$ \\
\hline Urine histidine, $\mu g / 24 \mathrm{~h} / 100 \mathrm{~g}$ body $w t$ & $327 \pm 17.5$ & $321 \pm 18.6$ & NS \\
\hline Urine flow, $m l / 24 h$ & $15.9 \pm 2.5$ & $26.8 \pm 2.4$ & $<0.005$ \\
\hline Histamine/creatinine ratio $\S$ & $1159 \pm 237$ & $2750 \pm 344$ & $<0.001$ \\
\hline Histidine/creatinine ratio" & $177 \pm 13$ & $143 \pm 7$ & NS \\
\hline
\end{tabular}

- For significance of differences between controls $(n=18)$ and PA nephrosis $(n=22) ; t$ test. $\$$ Mean \pm SE.

Ratio of urine histamine (nanograms) to urine creatinine $(\mathrm{mg} / 100 \mathrm{~g}$ body wt) excreted per $24 \mathrm{~h}$.

"Ratio of urine histidine (micrograms) to urine creatinine ( $\mathrm{mg} / 100 \mathrm{~g}$ body wt) excreted per $24 \mathrm{~h}$. 
experiments and on day 9 glomeruli and tubules were isolated from the renal cortex, as described in Methods. Histamine was determined in glomeruli and in tubules without (basal value) or after incubation with $1 \mathrm{mM}$ $\mathrm{L}$-histidine for $3 \mathrm{~h}$ similar to the experiment portrayed in Fig. 3. Histamine levels were, under all conditions, higher in glomeruli than in tubules (Table II). The content of histaimine was significantly higher in glomeruli from PA-nephrotic rats, compared with controls; similar but lesser difference in histamine content was observed in tubules. Incubation with L-histidine increased histamine level in glomeruli and to a lesser degree in tubules of PA-nephrotic rats (Table II). In concordance with other experiments (Fig. 3) histamine increase after incubation with L-histidine was found in glomeruli but not in tubules from control animals (Table II).

\section{DISCUSSION}

Actions of histamine in glomeruli, possibly mediated by cAMP $(21,24)$, are of major interest, especially in view of the known effect of this amine on capillary permeability $(5-7,45,46)$ in other microvascular beds. Circulating levels of histamine under normal conditions are very low $(13,47)$, therefore it is unlikely that histamine will reach the glomeruli through the circulation in sufficient quantities to induce physiologic effects. For example, in the rat plasma, histamine levels (Table I) were $<1 \mu \mathrm{M}$, a value very close to those

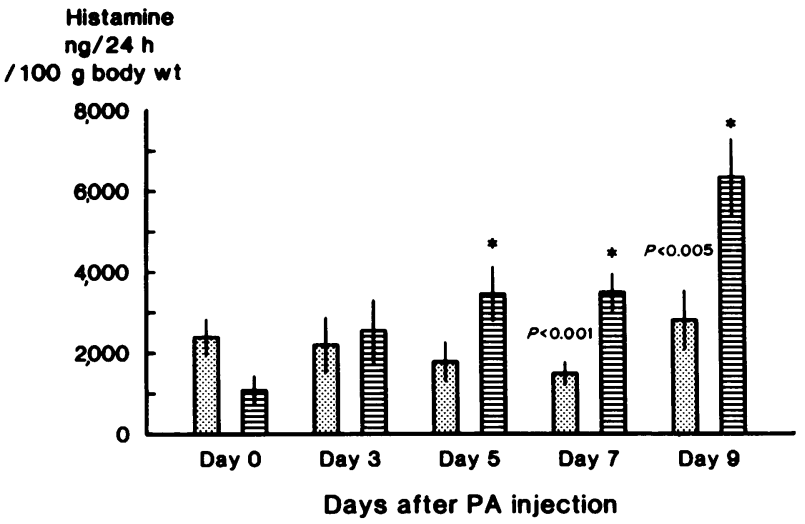

Figure 5 Urinary excretion of histamine in control rats injected with saline only (dotted bars) and in rats injected at day 0 with puromycin aminonucleoside (PA) (hatched bars) in the same dose as specified in Fig. 4 and in Methods; urinary excretion of histamine is expressed as nonograms excreted per $24 \mathrm{~h}$ per $100 \mathrm{~g}$ body wt. Each bar represents mean \pm SEM of 13-17 rats. Asterisk denotes significant increase $(P<0.05$ or higher degree of significance; paired $t$ test) in histamine excretion compared with values on day of $P A$ injection (day 0$)$. $P$ values between bars donote significance of differences between histamine excretion in PA-nephrotic rats and control rats on the same day.
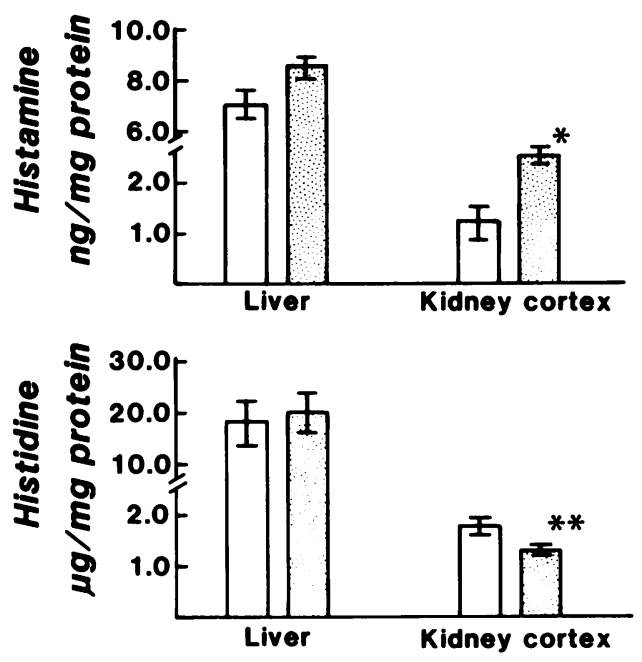

Figure 6 Histamine (upper panel) and histidine (lower panel) content in liver (left side) and in renal cortex (right side) in control animals (open bars) and animals with fully developed PA nephrosis, sacrificed on day 9 after injection of PA; for details see text. Bars represent mean $\pm \mathrm{SE}$ of 1215 rats. Denotes value significantly $(P<0.005 ; t$ test $)$ higher than controls. $\because$ Denotes value significantly $(P<0.025 ; t$ test) lower than controls.

reported by Almeida et al.(47), whereas histamine had a significant stimulatory effect on cAMP in glomeruli at concentrations of $1 \mu \mathrm{M}$ and higher (21).

In the rat kidney histamine was predominantly contained in the cortex (Fig. 2). Because histamine levels were very similar in cortex from perfused (Fig. 2) and nonperfused kidneys (see controls, Fig. 6), this suggests that histamine in the blood of renal vasculature contributes little to its total tissue content. Histamine content in glomeruli exceeds that in mixed population of renal cortical tubules (Fig. 3, Table II), which indicates that glomeruli are not only a site of histamine action on cAMP system (21-24), but also that it is contained in this structure in relatively high amounts. This finding is in basic agreement with the presence of histidine decarboxylase, in rat glomeruli (20). It should be stressed that the present results need not necessarily relfect quantitatively histamine distribution in vivo. Conceivable, histamine content in glomeruli and/or in tubules may be differentially changed in the course of the preparation that includes extensive rinsing with buffers (Methods) in such a way that the observed difference in histamine content may be higher or smaller than in situ. In addition, histamine may also be contained in other cortical structures besides glomeruli and tubules, such as vessels or interstitium (26).

Finding that incubation with L-histidine (Fig. 3) causes histamine increase only in glomeruli but not in tubules as well as a differential effect of bromocresine 
TABLE II

Histamine Content in Glomeruli and Cortical Tubules Isolated from Control Rats and Rats with (PA) Nephrosis at Day 9 after Injection of PA. For Details See Methods.

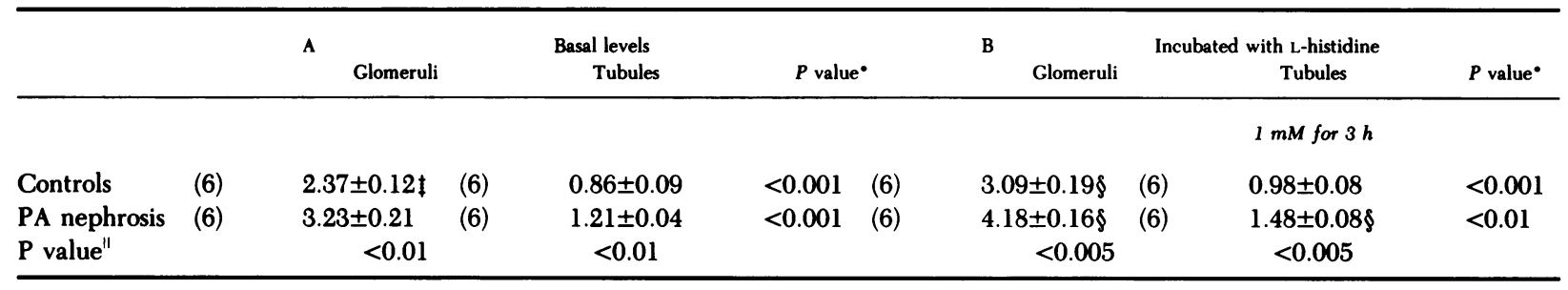

- For significance of differences between glomeruli and tubules $(t$ test).

I Mean \pm SEM (nanograms histamine/milligrams protein); in brackets $(n)$ number of observations.

$\$$ Significantly higher $(P<0.002 ; t$ test) compared with corresponding basal values (without incubation with L-histidine).

"For significance of differences between control and PA-nephrotic rats ( $t$ test).

(Fig. 3) suggest that the relatively high histamine content in glomeruli is likley due to de novo formation (20) from L-histidine in situ rather than due to slower rate of histamine catabolism in glomeruli. Capacity for histamine synthesis in glomeruli may be even higher than suggested by the present results. In our experiments, only one catabolic pathway-diamine oxidase (histaminase) - was inhibited with aminoguanidine $(45,48)$. Because the rat kidney has a very high activity of histamine methyltransferase (31) it cannot be excluded that some portion of de novo-synthesized histamine has been consumed through this other inactivation pathway (45). Detailed roles of all factors that may contribute to the relatively high histamine levels in glomeruli remain to be established.

The possible mechanism underlying the markedly increased urinary excretion of histamine in PA-nephrotic rats should be briefly considered. The observation of little or no differences between controls and PA-nephrotic rats in plasma histamine levels and in estimated glomerular filtration rate $^{2}$ suggest that enhanced urinary excretion of histamine may not be simply accounted for by increased filtered load of histamine. Several features appear to indicate that enhanced de novo synthesis $(26,49,50)$ of histamine in the kidneys of PA-nephrotic rats may be a likely source of enhanced urinary histamine. We found that in renal cortex (Fig. 6), in glomeruli, and to a lesser degree, tubules (Table II) of PA-nephrotic rats, tissue levels and accumulation of histamine are increased. Radiolabeled L-histidine injected into the renal artery (50) appears in urine as histamine. Conversely, radiolabeled histamine injected into the renal artery is rapidly taken up by tubules and extensively catabolized to inactive metabolites $(51,52)$. These observations support, at least indirectly, the possibility that increased urinary excretion of histamine in PA nephrosis is due to enhanced intrarenal histamine synthesis. However, the present study does not exclude the possibility that decreased tubular reabsorption of histamine or increased tubular secretion of histamine might account for (or contribute to) enhanced urinary histamine excretion in PA nephrotic rats.

Increased supply of L-histidine (13) by elevated plasma concentration or increased tissue levels of histidine could enhance synthesis and urinary excretion of histamine (53). Our findings show that urinary excretion of histidine was not different between control and PA-nephrotic animals (Table I), and that plasma levels, renal tissue content, and estimated filtered load of L-histidine were even lower in PA rats than in controls (Table I, Fig. 6). These data argue against the possibility that the higher histamine formation in PA nephrosis is due to the increased availability of L-histidine.

Results of our experiments on isolated nephron segments (Table II) point to glomeruli as a major intrarenal site of enhanced histamine synthesis and accumulation in PA nephrosis. Unlike in tubules from control kidneys, in the tubules of PA-nephrotic rats incubated with L-histidine (Table II) a small increase in histamine was observed, suggesting that PA nephrosis affected histamine dynamics also in cortical tubules. The mechanism of this effect is not apparent from present results and several possibilities exist. For example, if histamine catabolism via methylation pathway, which was not inhibited under present incubation conditions, is decreased in PA nephrosis, such as change might contribute to higher histamine accumulation in PA-nephrotic tubules. Interestingly, urinary histamine increases pari passu with proteinuria (Fig. 5). However, the question of whether the increase of the renal histamine in PA nephrosis is a causative factor or a consequence of this disease cannot be answered from the present data.

The possible relation of the enhanced intrarenal histamine synthesis and accumulation in glomeruli to pathophysiology of PA nephrosis should be briefly and 
very guardedly considered. It is of interest that locally applied histamine increased penetration of ferritin into glomerular basement membrane (54) as it occurs in PA nephrosis (55). In extrarenal capillary beds directly applied histamine increased transcapillary passage of proteins both in the peritoneum of rats $(5,6)$ and intestinal capillaries of cats (56). Infusion of histamine into the aorta caused complex changes of glomerular dynamics (12), some similar to that reported in PA nephrosis (59). On the other hand, no change in glomerular passage of macromolecules was observed (57). It should be stressed that the effect of endogeneously elevated histamine, due to its localization and quantity, may differ substantially from effects of the infused histamine.

The diverse information mentioned above is in general compatible with the possibility that increased intraglomerular histamine, perhaps acting through cAMP (24), may modulate glomerular functions: the permeability of the glomerular capillary wall as well as other cellular and metabolic processes in glomeruli (24). The questions of how and to what extent the glomerular histamine influences normal glomeruli and glomeruli in PA nephrosis ought to be analyzed in future studies.

In conclusion, our results demonstrate that the glomeruli contains relatively high quantity of histamine and that they are sites of de novo histamine synthesis. Increased renal content of histamine, namely in glomeruli, and increased urinary histamine excretion in PA nephrosis indicates that altered metabolism of this vasoactive amine may be an important feature of this syndrome and could potentially play a pathogenic role.

\section{ACKNOWLEDGMENTS}

The expert technical assistance of Mr. Hasan Moltaji and Mr. Thomas Haugen, as well as the excellent secretarial help of Bonnie Becker, are gratefully acknowledged.

This work was supported by U. S. Public Health Service Research National Institutes of Health grants AM-16105 and AM-08469, by the Mayo Foundation, by an Established Investigator Award (74-182) of the American Heart Association to Dr. Dousa, and by Veterans Administration Research Funds to Dr. Abboud. Dr. Abboud and Dr. Shah were recipients of a Research Fellowship from the U. S. Public Health Service training grant AM-07013, and Dr. Velosa was the recipient of U. S. Public Health Service Clinical Investigator Award AM-00662 from National Institute of Arthritis Metabolic, Digestive, and Kidney Diseases.

\section{REFERENCES}

1. Mallick, N. P. 1977. The pathogenesis of minimal change nephropathy. Clin. Nephrol. 7: 87-95.

2. Michael, A. F., E. Blau, and R. L. Vernier. 1970. Glomerular polyanion: alteration in aminonucleoside nephrosis. Lab. Invest. 23: 649-657.
3. Brenner, B. M., T. H. Hostetter, and H. D. Humes. 1978. Molecular basis of proteinuria of glomerular origin. $N$. Engl. J. Med. 298: 826-833.

4. Venkatachalam, M. A., and H. G. Rennke, 1978. The structural and molecular basis of glomerular filtration. Circ. Res. 43: 337-347.

5. Kahn, A., and E. Brachet. 1979. The permeability coefficient of albumin of the isolated rat mesentery. Biochim. Biophys. Acta. 588: 219-231.

6. Rasio, E. A. 1974. Metabolic control of permeability in isolated mesentery. Am. J. Physiol. 226: 962-968.

7. Bignold, L. P., and A. W. J. Lykke. 1979. Time course and refractiveness of enhanced vascular permeability induced by histamine, serotonin and bradykinin in synovials of the rat. Experientia (Basel). 35: 1645-1647.

8. Feigen, L. P., B. M. Chapnick, and J. E. Flemming. 1978. Prostaglandins. Renal vascular responses to bradykinin, histamine and nitroglycerine. Am. J. Physiol. 234: H496-H502.

9. Bokesoy, T. A., and R. K. Turker. 1974. The presence of histamine $\mathrm{H}_{2}$-receptors in rabbit kidney. Arch. Int. Pharmacodyn. 209: 144-149.

10. Banks, R. O., J. D. Fondacaro, M. M. Schwaiger, and E. D. Jacobson. 1978. Renal histamine $H_{1}$ and $H_{2}$ receptors: characterization and functional significance. Am. J. Physiol. 235: F570-F575.

11. Campbell, W. B., and H. D. Itskovitz. 1976. Effect of histamine and antihistamines on renal hemodynamics and functions in the isolated perfused canine kidney. $J$. Pharmacol. Exp, Ther. 198: 661-667.

12. Ichikawa, I., and B. M. Brenner. 1979. Mechanisms of action of histamine and histamine antagonists on the glomerular microcirculation in the rat. Circ. Res. 45: 737-745.

13. Horakova, Z., H. R. Keiser, and M. A. Beaven. 1977. Blood and urine histamine levels in normal and pathological states as measured by a radiochemical assay. Clin. Chim. Acta. 79: 447-456.

14. Beaven, M. A., and Z. Horakova. 1978. The enzymatic isotopic assay of histamine. In Handbook of Experimental Pharmacology. M. Rocha de Silva, editor. SpringerVerlag, Berlin. 151-173.

15. Veilleux, R. 1975. Mast cells increase in the duodenum and kidney of magnesium deficient rats. Lab. Invest. 33: 80-87.

16. H. Selye. 1965. Regional distribution of mast cells in the kidney. In The Mast Cells. Butterworth Ind., Washington, D. C.

17. Sagher, F., and Z. Even-Paz. 1967. Mast cells and renal disease. In Mastocytosis and the Mast Cell. Year Book Medical Publishers, Inc., Chicago.

18. Henningsson, S. S. G., and E. Rosengren. 1971. Distribution of histidine decarboxylase in the pregnant mouse kidney. Q. J. Exp. Physiol. Cogn. Med. Sci. 56: 156159.

19. Juhlin, L. 1967. Determination of histamine in small biopsies and histological sections. Acta Physiol. Scand. 71: 30-36.

20. Heald, J. I., and T. M. Hollis. 1976. Histidine decarboxylase-mediated histamine synthesis in glomeruli from rat kidneys. Am. J. Physiol. 230: 1349-1353.

21. Torres, V. E., T. E. Northrup, R. M. Edwards, S. V. Shah, and T. P. Dousa. 1978. Modulation of cyclic nucleotides in isolated rat glomeruli. J. Clin. Invest. 62: 1334-1343.

22. Shah, S. V., T. E. Northrup, Y. S. F. Hui, and T. P. 
Dousa. 1979. Action of serotonin (5-hydroxytryptamine) and cyclic nucleotides in glomeruli of rat renal cortex. Kidney Int. 15: 463-472.

23. Abboud, H. E., S. V. Shah, and T. P. Dousa. 1979. Effect of dexamethasone on cyclic nucleotide accumulation in glomeruli. J. Lab. Clin. Med. 94: 708-717.

24. Dousa, T. P., S. V., Shah, and H. E. Abboud. 1980. Potential role of cyclic nucleotides of glomerular pathophysiology. Adv. Cyclic. Nucleotide Res. 12: 285-299.

25. Slovach, S. A., and B. Uvnas. 1968. Amine formation by rat mast cells in vitro. Acta Physiol. Scand. 73: 457-470.

26. Beaven, M. A. 1978 . Histamine: its role in physiologic and pathological processes. In Monographs in Allergy. S. Karger, Basel, New York, 1-113.

27. Zeiger, R. S., D. L. Yurdin, and F. J. Twarog. 1976. Histamine metabolism. I. Thin-layer radiochromatographic assays for histaminase and histidine decarboxylase. J. Lab. Clin. Med. 87: 1065-1074.

28. Taylor, K. M., and S. H. Snyder. 1972. Isotopic microassay of histamine, histidine, histidine decarboxylase and histamine methyltransferase in brain tissue. J. Neurochem. 19: 1343-1358.

29. Synder, S. H., R. Baldessalini, and H. Axelrod. 1966. A sensitive and specific enzymatic isotopic assay for tissue histamine. J. Pharmacol. Exp. Ther. 153: 544-549.

30. Glasser, J. R., J. A. Velosa, and A. F. Michael. 1977. Experimental model of focal sclerosis. I. Relationship to protein excretion in aminonucleoside nephrosis. $L a b$. Invest. 36: 519-526.

31. Shaff, R. E., and M. A. Beaven. 1979. Increased sensitivity of the enzymatic isotopic assay of histamine: measurement of histamine in plasma and serum. Anal. Biochem. 94: 425-430.

32. Plaut, M., and L. M. Lichtenstein. 1978. Histamine, 5hydroxytryptamine, SRS-A: Discussion of type I hypersensitivity (anaphylaxis) in inflammation. J. R. Vane, and S. H. Ferreira, editors. Springer-Verlag, Berlin, Heidelberg, New York, 345-373.

33. Beaven, M. A., and S. Jacobson. 1971. A new assay for histaminase activity: measurement of tritiated water from $\beta$ (side chain label) ${ }^{3} \mathrm{H}$-Histamine. J. Pharmacol. Exp. Ther. 176: 52-64.

34. Diamant, S., and E,. Shafrir. 1974. Lipogenesis in Aminonucleoside-Induced Nephrotic Syndrome. Biochim. Biophys. Acta. 360: 241-251.

35. Henry, J. R., and C. P. Szustkiewicz. 1974. The preparation of protein-free filtrates, In Clinical Chemistry. Principles and Techniques. Richard J. Henry, Donald C. Cannon, and James W. Winkelman, editors. Harper and Row. 389-404.

36. Beaven, M. A., S. Jacobsen, and Z. Horakova. 1972. Modification of the enzymatic isotopic assay of histamine and its application of measurements of histamine in tissues, serum, and urine. Clin. Chim. Acta. 37: 91-103.

37. Shore, P. A., A. Burkhalter, and V. H. Cohn. 1959. A method for the fluorometric assay of histamine in tissues. J. Pharmacol. Exp. Ther. 127: 182-186.

38. Brown, D. D., R. Tomchick, and J. Axelrod. 1959. The distribution and properties of a histamine-methylating enzyme. J. Biol. Chem. 234: 2948-2950.

39. Ambrose, J. A., A. Crimm, J. Burton, K. Paullin, and C. Ross. 1969. Fluorometric determination of histidine. Clin. Chem. 15: 361-366.
40. Lowry, O. H., N. J. Rosenbrough, A. L. Farr, and R. J. Randall. 1951. Protein measurement with the folin phenol reagent. J. Biol. Chem. 193: 265-275.

41. Hiller, A., R. L. Freig, and W. W. Beckman. 1949. Determination of protein in the urine by the biuret method. J. Biol. Chem. 176: 1421-1429.

42. Levinson, S. A., and R. P. MacFate. 1969. Clinical Laboratory Diagnosis. Lea and Febiger, Philadelphia, $\mathrm{Pa}$. 7th edition 413-415.

43. Shah, S. V., S. A. Kempson, T. E. Northrup, and T. P. Dousa. 1979. Renal adaptation to a low phosphate diet in rats. Blockade by actinomycin D. J. Clin. Invest. 64: 955-966.

44. Velosa, J. A., R. J. Glaser, T. E. Nevins, and A. F. Michael. 1977. Experimental model of focal sclerosis. II. Correlation with immunopathologic changes, macromolecular kinetics, and polyanion loss. Lab. Invest. 36: 527-534.

45. Beaven. M. A. 1976. Histamine. New Engl. J. Med. 294: $30-36$, and 320-325.

46. Renkin, E. M., R. D. Carter, and W. L. Joyner. 1974. Mechanism of the sustained action of histamine and bradykinin on transport of large molecules across capillary walls in the dog paw. Microvasc. Res. 7: 49-60.

47. Almeida, A. P., W. Flye, D. Deveraux, Z. Horakova, and M. A. Beaven. 1980. Distribution of histamine and histaminase (diamine oxidase) in blood of various species. Comp. Biochem. Physiol. 67C: 187-190.

48. Maslinski, C. 1975. Histamine and its metabolism in mammals. Part II: catabolism of histamine and histamine liberation. Agents and Actions. 5: 183-225.

49. Schayer, R. W., K. Y. T. Wu, and R. L. Smiley. 1954. Sources of urinary histamine in the rat. Am. J. Physiol. 179: 481-485.

50. Lindell, S. E., and R. W. Schayer. 1958. Formation of histamine in the kidney of the dog. Br. J. Pharmacol. 13: 89-90.

51. Lindell, S. E., and R. W. Schayer. 1958. Metabolism of injected $\left[{ }^{14} \mathrm{C}\right]$ histamine in the kidney of the dog. $\mathrm{Br} . J$. Pharmacol. 13: 52-53.

52. Lindell, S. E., and R. W. Schayer. Renal removal of injected $\left[{ }^{14} \mathrm{C}\right]$ histamine from the blood of dogs. $\mathrm{Br} . J$. Pharmacol. 13: 44-51.

53. Taylor, K. M., and S. H. Snyder. 1972. Dynamics of the regulation of histamine levels in mouse brain. J. Neurochem. 19: 341-354.

54. Shimamura, T. 1978. Effects of inflammatory mediators on the glomerular localization of intravenously administered ferritins. Experientia (Basel). 34: 1196-1197.

55. Farquhar, M. G., and G. E. Palade. 1961. Glomerular permeability. II. Ferritin transfer across the glomerular capillary wall in nephrotic rats. J. Exp. Med. 114: 699716 (and plates 61-73).

56. Mortillaro, N. A., D. N. Granger, P. R. Kvietys, G. Rutilli, and A. E. Taylor. 1981. Effects of histamine and histamine antagonists on intestinal capillary permeability. Am. J. Physiol. 240: G381-G386.

57. Bohrer, M. P., C. Baylis, C. R. Robertson, and B. M. Brenner. 1977. Mechanisms of the puromycin-induced defects in the transglomerular passage of water and macromolecules. J. Clin. Invest. 60: 152-161. 